\title{
Shifting workstyle to teleworking as a new normal in face of COVID-19: analysis with the model introducing intercity movement and behavioral pattern
}

\author{
Kenji Karako', Peipei Song ${ }^{2}$, Yu Chen ${ }^{1}$, Wei Tang ${ }^{3}$ \\ ${ }^{1}$ Department of Human and Engineered Environmental Studies, Graduate School of Frontier Sciences, The University of Tokyo, Chiba, Japan; \\ ${ }^{2}$ Institute for Global Health Policy Research, Bureau of International Health Cooperation, ${ }^{3}$ International Health Care Center, National Center for \\ Global Health and Medicine, Tokyo, Japan \\ Contributions: (I) Conception and design: P Song, Y Chen; (II) Administrative support: Y Chen, W Tang; (III) Provision of study materials or patients: \\ All authors; (IV) Collection and assembly of data: K Karako, P Song; (V) Data analysis and interpretation: K Karako, P Song; (VI) Manuscript \\ writing: All authors; (VI) Final approval of manuscript: All authors. \\ Correspondence to: Peipei Song. Senior Research Fellow, Institute for Global Health Policy Research, Bureau of International Health Cooperation, \\ National Center for Global Health and Medicine, 1-21-1 Toyama, Shinjuku, Tokyo 162-8655, Japan. Email: ppsong-tky@umin.ac.jp; Yu Chen. \\ Professor, Department of Human and Engineered Environmental Studies, Graduate School of Frontier Sciences, The University of Tokyo, 5-1-5 \\ Kashiwa-no-ha, Kashiwa, Chiba 227-8568, Japan. Email: chen@edu.k.u-tokyo.ac.jp.
}

Background: Instead of the complete lockdown, since the outbreak of coronavirus disease 2019 (COVID-19), Japan has been trying to control the infection by self-restraint request policy. It seems that the number of infected people has subsided, however, the increasing human activities again in the resumption of economy may lead to the second wave of infections. Here, we analyzed the major factors behind the success control of the first outbreak in Japan and the potential risk of the second wave.

Methods: Employing a localized stochastic transition model, we analyze the real data and the results of simulation in Tokyo from March 1 to July 31. In the model, population is divided into three compartments: susceptible, infected, and removed; and area into three zones: crowded, mid and uncrowded. Different zones have different infection probabilities characterized by the number of people gathered there. The flow of the infection simulation in one day consists of three steps: (I) intercity movement of population, (II) isolating infected people, and (III) zone shifting following group behavioral patterns.

Results: The major cause for the success of controlling the first outbreak in Tokyo is demonstrated through our simulation to be the early request of self-restraint as well as the early detection of infected people. Meanwhile, the observation that the increasing human activities again in the resumption of economy will lead to the second wave of infections is also found in the simulation with an extended period. Based on the analysis of intercity movement and behavioral pattern on Tokyo where normally about 2.9 million people come from the surrounding cities to the central area by using the public railway system every day, results showed that turning the workstyle of 55\% of working people ranging in age from 20 to 64 years old into teleworking (remote work) may control the spread of infection without significant economic damage. Meanwhile, to keep about $75 \%$ of the normal activity level and to advocate the shift to telework are indispensable because a sudden resumption of activity from the lockdown sate can rapidly spread infection.

Conclusions: As a new normal in face of COVID-19 for Tokyo and other cities that with a high population density, shifting the workstyle of $55 \%$ of working people to teleworking and to reduce $25 \%$ time staying in the high infection risk area could be an effective measure to control the spread of infection while maintaining a certain level of economic activity.

Keywords: Coronavirus disease 2019 (COVID-19); Japan; Tokyo; transmission; infection; modeling; susceptibleinfected-removed (SIR) 
Submitted Jul 15, 2020. Accepted for publication Aug 07, 2020.

doi: 10.21037/atm-20-5334

View this article at: http://dx.doi.org/10.21037/atm-20-5334

\section{Introduction}

The outbreak of coronavirus disease 2019 (COVID-19) poses a serious threat to global health and economies. The pathogen has been identified as a novel enveloped RNA betacoronavirus that named severe acute respiratory syndrome coronavirus 2 (SARS-CoV-2) (1-3). The diagnostic approaches for COVID-19 include nucleic acid detection, chest computed tomographic (CT), epidemiological history and clinical manifestations. It presents a wide range of clinical presentation, from asymptomatic or mildly symptomatic patients to those requiring intensive care (4-6). Currently, hundreds of clinical trials on a wide variety of treatments against COVID-19 are being conducted around the world (7).

On March 11, 2020, the World Health Organization (WHO) declared COVID-19 as a pandemic (8). As of July 11 , the number of confirmed cases has increased to 12.4 million and over 559,000 people have unfortunately lost their lives (9). Stringent public health and social measures (PHSM) have been put in place to slow down the spread of COVID-19, and even the measure of complete lockdown has been installed in some cities, such as Wuhan, China.

In Japan, the first domestic COVID-19 transmission was reported in January 2020. As of July 11, there were 21,113 domestic cases have been confirmed, including 981 deaths (10). Japan's death rate per capita from COVID-19 is one of the lowest in the world. Instead of the complete lockdown, since the outbreak of COVID-19, Japan has been trying to control the infection by self-restraint request policy calls for the avoidance of "closed spaces, crowded places, and closecontact settings" to the greatest extent. This policy focuses on reducing the epidemic peak by prioritizing treatment for those who are at risk of developing serious pneumonia, and on avoiding the collapse of public health-care service as well.

Characterized by "limited fatality despite loose restriction" (11), Japan is a country that claims to have succeeded in controlling COVID-19 first outbreak without complete lockdown. In early April, the number of infected people per day in Japan, especially Tokyo, exceeded tripledigits $(12,13)$. The Japanese government declared a state of emergency on April 7 in order to control the spread of infection and urged the people to refrain from unnecessary outings (14). As of May 25, the Japanese government has lifted the state of emergency because the average number of infected people per day fell to below 20 and the risk of large-scale infection spread has been decreased (15). By May 25, there were 16,445 known cases of infection, of which 5,159 were found in Tokyo (16), accounting for about $31 \%$ of cases in Japan. It seems that the number of infected people has subsided from April to June, however, after lifting the state of emergency, the increasing human activities again in the resumption of economy may lead to the second wave of infections. In Tokyo, 224 new cases were reported on July 9 and 243 new cases reported on July 10, 2020 (17), and currently, Tokyo is the city with the largest number of confirmed cases of COVID-19 in Japan.

There are some studies analyzing future trends of COVID-19 in Japan (18-20), especially analyzing the peak or increasing trend of infected people. However, the analysis of intercity movement and behavioral pattern with different activity levels by employing a localized stochastic transition model has not been fully investigated. In this study, analysis with the model introducing intercity movement and behavioral pattern is conducted on Tokyo, which has a high population density and is the city with the largest number of confirmed cases of COVID-19 in Japan currently, with the purpose to provide the data reference for COVID-19 epidemic control for Tokyo and other cities worldwide that with a high population density.

In this study, employing a localized stochastic transition model, we analyzed the major factors behind the success control of the first outbreak in Japan and the potential risk of the second wave. Furthermore, based on the analysis of intercity movement and behavioral pattern with different activity levels, we will discuss the effectiveness of suppressing the infection by reducing the amount of activities with non-mandatory restrictions, and propose ways to control the spread of infection while maintaining a certain level of economic activity.

\section{Methods}

\section{Localized stochastic transition model}

In the previous study, the spread of COVID-19 in Japan was 
treated as a transmission in a closed system and studied with a stochastic transition model. To this end, we proposed a formulation for the stochastic transition of agents' state with reference to SIR (susceptible-infected-removed) model (18). The considered area is divided into three zones: crowded, mid and uncrowded, which is an abstract area where people spend time and characterized by the number of people. The average time of meal, commute, and work per day for Japanese people is about eight hours, and at that time people spend in an area likely to contact with other people, thus it is considered as a person is staying in a crowded zone. On the other hand, the situation of sleeping is considered as staying in uncrowded zone because there is little contact with people. In addition, the mid zone is an intermediate concept between above two. Different infection rates are applied in different zones. For example, susceptible transitions into infected every hour with a probability determined by both the tag of area zone and the ratio of infected in that zone. Moreover, people migrate among different zones following a uniform behavioral pattern which specify how long they should spend in a certain zone.

In this study, as the focus is on the modeling of the spread of infections in Tokyo area, intercity commuting is added to the previous model by taking into account the transportation characteristics of Tokyo, namely a large influx of population from surrounding cities. In addition, people follow different behavior patterns according to the specific groups to which they belong. The inclusion of nonuniform behavioral pattern is inspired by the observation that, under the government intervention, such as the declaration of state of emergency, recommendations of telework and school closures, people are likely to adopt different behavioral patterns according to their different social status.

\section{Flow of simulation}

In Tokyo, normally about 2.9 million people come from outside to the central area by using the public railway system every day (21). Most people come from the surrounding cities for commuting to work or school. We define Tokyo and its surrounding cities, including Chiba, Kanagawa, Saitama, Tochigi, Gunma, and Ibaraki as individual semi-closed systems, and take the intercity movement of people into consideration. Different numbers of susceptible, infected, removed are initialized in different cities according to the real data.

As shown in Figure 1, the flow of infection simulation in a single day consists of three steps: (I) intercity movement of population, (II) isolating infected people, and (III) zone shifting following group behavioral patterns and the local infection of susceptible. In step (I), a certain fraction of people is randomly selected in each city and put into another city. People who moved to other cities are temporarily counted as the local person in the destination city within that day. In step (II), all infected in the city are segregated and transition to removed with the removal probability in that city with $d$ defined as date. In step (III), first susceptibles in each city enter into different zones according to behavioral patterns of the group to which they belong. Next, susceptible is infected and transitions to infected with the infection probability $P_{\text {zone, infection }}(d)$ on day $d$. After completing all steps, the commuting people will return to their original cities. All the above steps are repeated as a routine process for each individual in all the cities.

\section{Infection and removed probabilities}

The zonal infection probability $P_{z o n e, \text { infection }}(d)$ indicates the rate of getting infected when a susceptible person stays in a specific zone area. Note that each city consists of three zones including crowded zone, mid zone and uncrowded zone, assigned with different zonal infection probabilities. As the zonal infection probability can be influenced not only by the characteristics of the zone but also by the proportion of infected in that city, it is decided as the following

$$
\begin{aligned}
& P_{\text {zone, infection }}(d)=\alpha_{z o n e} R_{C, \text { Infected }}(d) \\
& R_{C, \text { Infected }}(d)=\frac{N_{C, \text { Infected }}(d)}{N_{C}(d)}
\end{aligned}
$$

where $\alpha_{z o n e}$ denotes the baseline probability of infection in the zone where the susceptible stay, and $P_{c, \text { Infected }}(d)$ denotes the ratio of infected in city $C$ on day $d$. The number of infected and the total number of people in the city are denoted as $N_{C, \text { Infected }}(d)$ and $N_{C}(d)$.

Denoted as $P_{\text {Removed }}(d)$, the probability of transition from infected to removed is set independent of cities. It is related to the speed at which infected is detected in reality, which depends on the number of PCR tests performed per day. Correspondingly, $P_{\text {Removed }}$ is given by

$$
P_{\text {Removed }}(d)=\left\{\begin{array}{c}
\frac{\beta_{\text {term }}}{10}(\text { if d is holiday }) \\
\beta_{\text {term }} \text { else }
\end{array}\right.
$$

where $\beta_{\text {term }}$ denotes the baseline probability for the removal of 


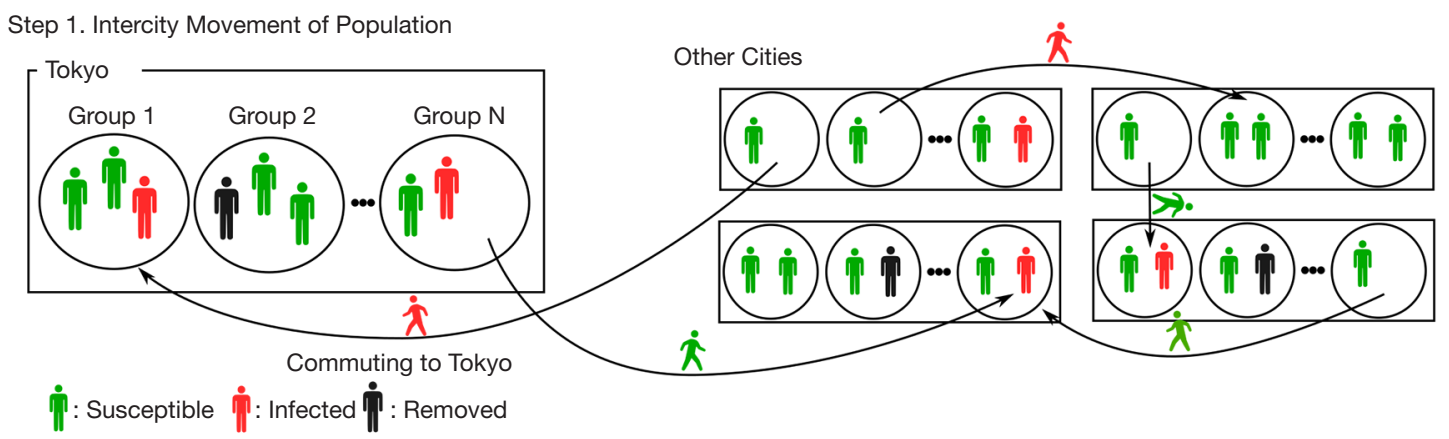

Step 2. Isolating Infected People

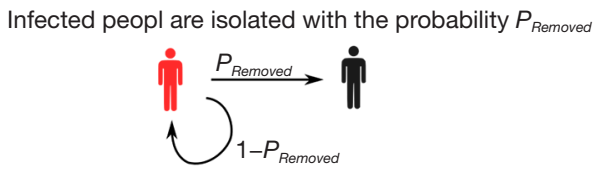

Step 3. Zone Shifting following Group Behavioral Patterns
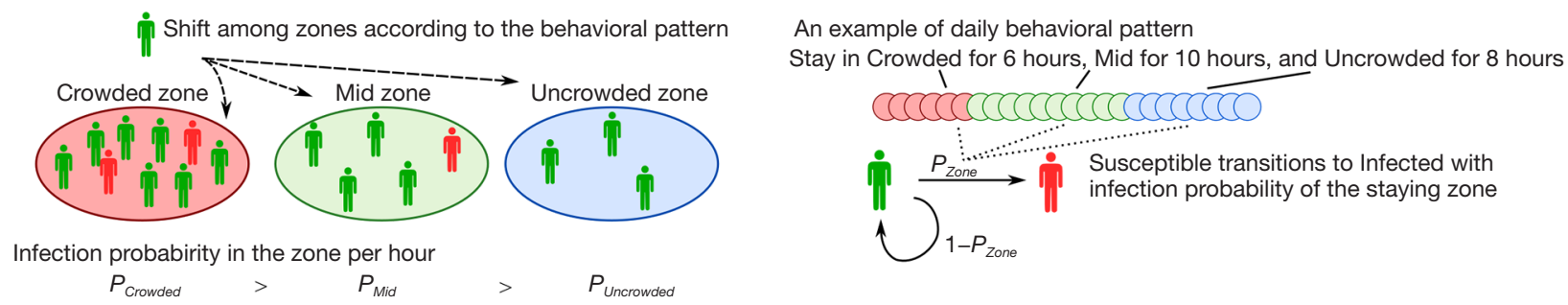

Figure 1 The Flow of localized stochastic transition model in Tokyo.

infected. The simplest model set $\beta_{\text {term }}$ as a constant. However, considering the increase in the number of PCR tests and the widespread recognition of COVID-19 symptom, which makes the disease easier to be detected at an earlier stage, $\beta_{\text {term }}$ can also be shifted upward continuously. The reason for reducing the value to $1 / 10$ on holidays is that the Japanese PCR test institutions have days off.

\section{Grouping of population}

To reflect the actual state of Tokyo after March, the population is divided into several groups in consideration of both the age and the effects of declaration of the state of emergency. Three major groups are assembled by age as Group I (under 20 years old), Group II (20 to 64 years old), and Group III (65 years old and over). Group I and Group III are further divided into two sub-groups: A (the normal) and B (the active). Group II is divided into four sub-groups: A (the normal), B (the active), C (complete telework) and D (partial telework). Group II-C and Group II-D stand for the change of working style in response to the declaration of the state of emergency, recommendations to telework and school closures by the Japanese government. Note that each group has a distinct behavior pattern, according to which people decide the duration in which they stay in the three zones.

\section{Results}

\section{Simulation of infection spread before lifting the state of emergency in Tokyo}

The infection spread from March 1 to May 24 (before lifting the state of emergency) in Tokyo were analyzed, model parameters were set as $\alpha_{\text {crovuded zone }}=2 \%, \alpha_{\text {mid zone }}=0.2 \%$, and $\alpha_{\text {uncrovded zone }}=0.02 \%$ with reference to the values used in the previous study (18).

Table $S 1$ shows the initial number of people in each group and the initial number of people who are susceptible, infected, or removed. The total population and age distribution for each city are set with reference to the values 

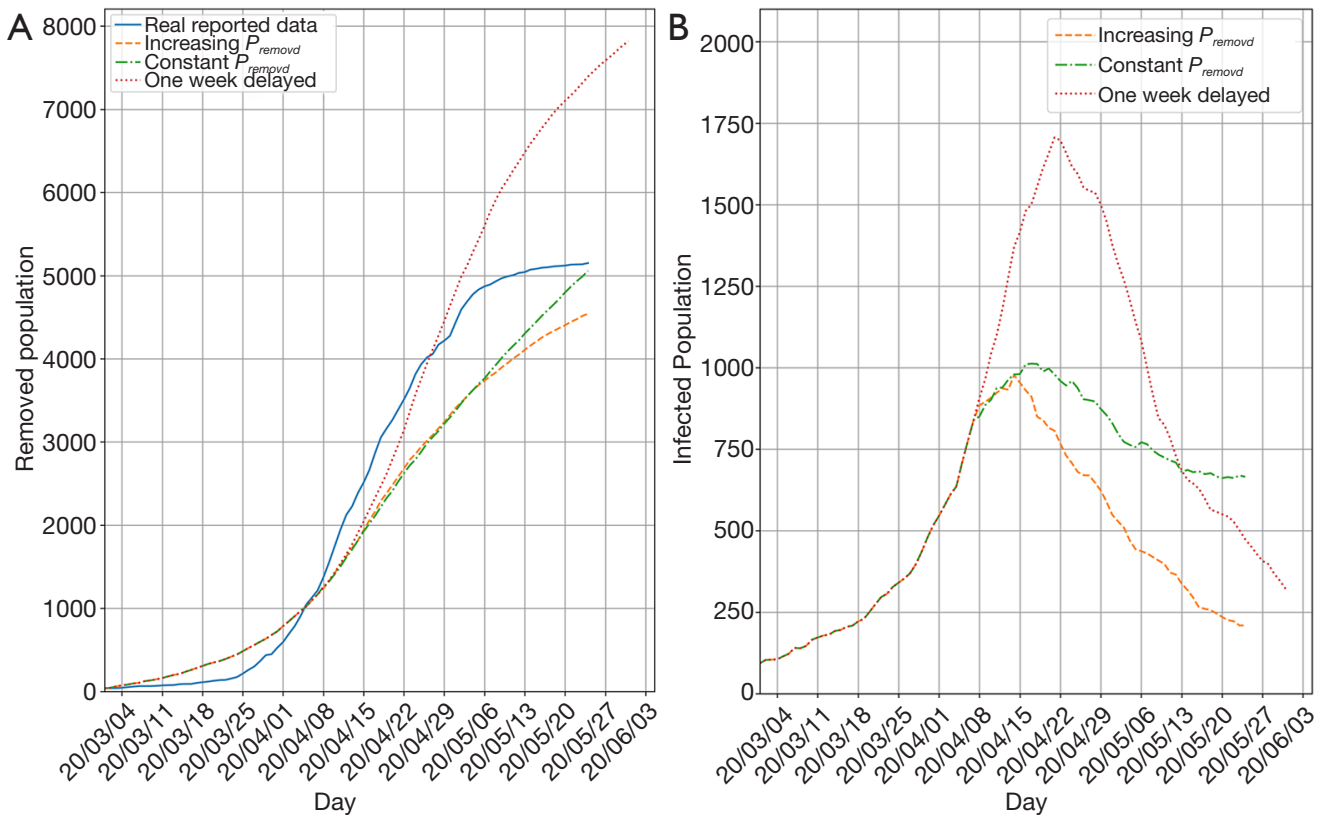

Figure 2 Infection transition in Tokyo of the real data and the results simulated by localized stochastic transition model. (A) Transition of the number of removed or people reported as COVID-19. (B) Transition of the number of infected.

announced by each prefecture (22-28). The initial number of removed in each city is set as the number of infected persons found in each city as of February 29 (29). The initial number of susceptible in Tokyo is set as 2.5 times the number of removed, and the initial number of susceptible in other city is set as 1.5 times the number of removed. Initial values of removed and susceptible are assigned to each group according to the age distribution of infected person in Japan (29). Based on the fact that the number of train passengers declined in Tokyo in March (30), 25\% of Group II members (20 to 64 years old) is put into the $\mathrm{C}$ subgroup (complete telework) and $35 \%$ of the group members is put into the D subgroup (partial telework). Moreover, $10 \%$ of the total members in Group I, II and III belong to the active subgroup, while the rest belongs to the normal subgroup.

Table $S 2$ shows the baseline removal probability, from March 1 to May 24, the day right before the state of emergency declaration was lifted. There are two settings of $\beta_{\text {term }}$ for comparison, one as a constant and the other as an increasing value. Tables $S 3$ and $S 4$ display the number of people commuting between cities and the behavioral patterns for each group during the same period. The behavioral pattern of each group is adjusted so that people stay in three zones for an average of 8 hours.
A virtual scenario is also simulated under the assumption that the declaration of state of emergency was delayed to April 14. Behavior patterns are the same as above, except that all the dates shift one week forward.

Simulation results with parameters above and the actual cumulative number of people confirmed as COVID-19 in Tokyo are shown in Figure 2. In addition, the transitioning number from susceptible to removed per day in the simulation and the actual growth number of people confirmed as COVID-19 in Tokyo (13) are shown in Figure 3.

As shown in Figure 2, with an increasing removal probability, the number of infected reaches 4,576 on May 24, while the actual number is 5,151. In Figure 3, the transitioning number from susceptible to infected with an increasing removal probability reaches its peak around April 16 and converges around May 21, similar to the actual data in Tokyo, On the other hand, the fixed removal probability makes no difference to the timing of infected peak, but it delays the process of convergence. Lastly, it can be seen that if the declaration of the emergency state were delayed by one week, the number of infected would be enlarged and eventually reach the peak number more than 1.5 times the actual number of persons confirmed as COVID-19 in Tokyo. 


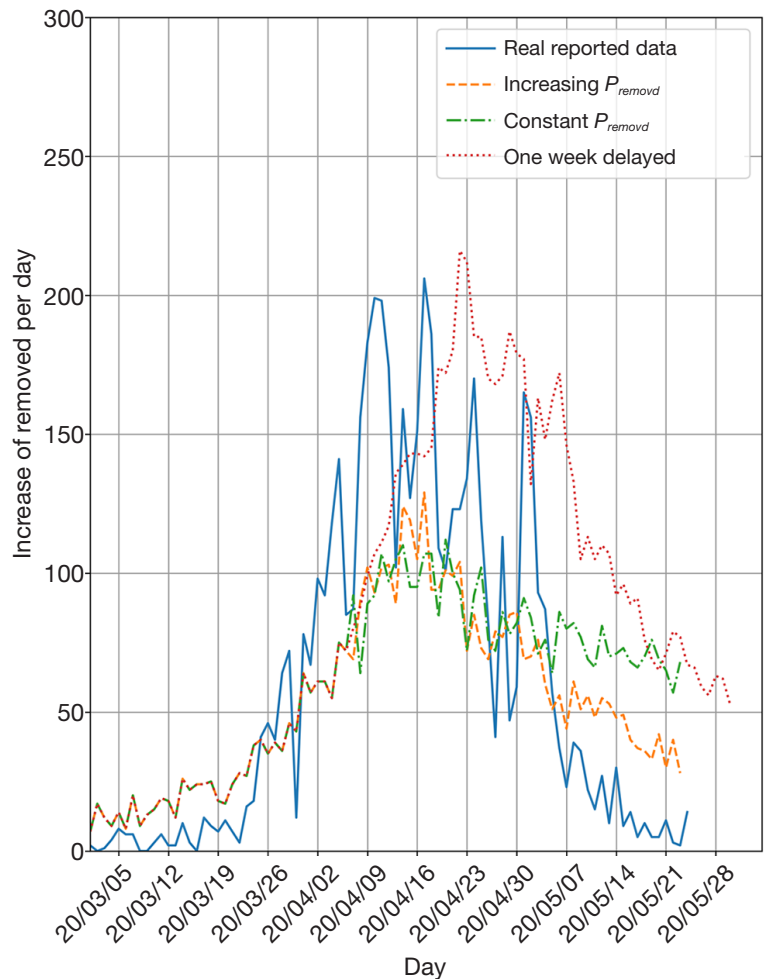

Figure 3 Increase of removed and people reported as COVID-19 per day in Tokyo.

\section{Simulation of infection spread after lifting the state of emergency in Tokyo}

The state of emergency was lifted on May 25, though there is still a probability of another wave of infection coming to the great Tokyo area. In this study, the spread of infection is further simulated up to July 31, 2020 under several possible scenarios. Results from March 1st to May 24, including the population of susceptible, infected and removed, are used as initial conditions and the increasing removal probability $P_{\text {Removed }}$ is applied to the subsequent simulations.

Behavioral patterns are specified for six scenarios as shown in Table 1. The behavioral pattern of Scenario A is identical with that used in March, except Group IA members are allowed to go to school. In Scenarios B and $\mathrm{C}$, the active members of each group reduce their duration of stay in the crowded zone to $75 \%$ and $50 \%$ of that in Scenario A, respectively. In Scenarios D, E and F, durations of stay in the crowded zone are set uniformly to 8,6 and 4 hours irrespective of the characteristics of different subgroups.

Predictions of the spread of infection from May 25 to
July 31 under different scenarios are shown in Figure 4. For Scenarios $\mathrm{A}$ and $\mathrm{D}$, in which activities are almost recovered to the normal level, it can be seen that the number of removed increases by 5,000 in two months. For Scenarios B and $\mathrm{E}$, the number of removed increases almost constantly and reaches about 2,000 in two months. Subsiding of the spread of infection can only be observed in Scenarios C and $\mathrm{F}$ where the size of infected population decays gradually.

\section{Effects of increasing telework population}

The result of Scenario A shows that occurrence of the second wave of infections is possible if the activity level returns to that in March, before the declaration of the emergency state. On the other hand, the government has been promoting telework since late February. Correspondingly, complete telework has been realized in some companies, however, only the partial telework is implemented in others.

Scenarios A and B are used as reference, where $25 \%$ of Group II (from 20 to 64 years old) members are completely doing the telework. To compare with the reference scenarios, new scenarios are added as A40/B40, where $40 \%$ of Group II members are set as the complete teleworkers; and also as A55/B55, where $55 \%$ of the same group members are set as the complete teleworkers. Results of predicting the control of infection spread under the new scenarios are shown in Figure 5. In Scenarios A40 and B40, the effect of shifting to telework is negligible and the infected number reaches almost the same level in Scenarios A and B. On the other hands, the number of infected decreases gradually in Scenarios A55 and B55 showing that the shift to telework is effective, only if more than half of the workers respond to the government's promotion.

\section{Discussion}

The famous SIR epidemiological model was mainly used in previous studies on analysis and prediction of the COVID-19 epidemic in Japan (18-20). The main difference between the model used in the current study and SIR model is the inclusion of locality and heterogeneity. With the localization, intercity movements can be taken into account so that the increase of infected number in late March in the Kanto area caused by the influx/outflux of population to/ from Tokyo can be well captured. On the other hand, the application of heterogeneous behavioral pattern to different groups of population render our model closer to the realistic 


\section{Annals of Translational Medicine, Vol 8, No 17 September 2020}

Page 7 of 11

Table 1 Behavioral pattern of each group that represents the time spent per day in each zone for different activity scenarios after lifting the state of emergency

\begin{tabular}{|c|c|c|c|c|c|c|c|c|c|c|c|c|c|c|c|c|c|c|}
\hline \multirow{4}{*}{ Scenario } & \multirow{4}{*}{ Term } & \multirow{4}{*}{ Zone } & \multicolumn{16}{|c|}{ Time staying at each place per day (hour) } \\
\hline & & & \multicolumn{4}{|c|}{ Age: 0-19 } & \multicolumn{8}{|c|}{ Age: 20-64 } & \multicolumn{4}{|c|}{ Age: 65 } \\
\hline & & & \multicolumn{2}{|c|}{ Normal } & \multicolumn{2}{|c|}{ Active } & \multicolumn{2}{|c|}{ Normal } & \multicolumn{2}{|c|}{ Active } & \multicolumn{2}{|c|}{ Complete telework } & \multicolumn{2}{|c|}{ Partial telework } & \multicolumn{2}{|c|}{ Normal } & \multicolumn{2}{|c|}{ Active } \\
\hline & & & Weekdays & Holidays & Weekdays & Holidays & Weekdays & Holidays & Weekdays & Holidays & Weekdays & Holidays & Weekdays & Holidays & Weekdays & Holidays & Weekdays & Holidays \\
\hline \multirow[t]{3}{*}{ A } & $05 / 25-07 / 31$ & Crowded & 8 & 8 & 12 & 12 & 10 & 10 & 12 & 12 & 4 & 8 & 10 & 10 & 6 & 6 & 12 & 12 \\
\hline & & Mid & 8 & 8 & 6 & 6 & 6 & 6 & 6 & 6 & 12 & 8 & 6 & 6 & 10 & 10 & 6 & 6 \\
\hline & & Uncrowded & 8 & 8 & 6 & 6 & 8 & 8 & 6 & 6 & 8 & 8 & 8 & 8 & 8 & 8 & 6 & 6 \\
\hline \multirow[t]{2}{*}{ B } & $05 / 25-07 / 31$ & Crowded & 6 & 6 & 9 & 9 & 8 & 7 & 9 & 9 & 4 & 6 & 8 & 7 & 4 & 5 & 9 & 9 \\
\hline & & Mid & 10 & 10 & 7 & 7 & 8 & 9 & 7 & 7 & 12 & 10 & 8 & 9 & 12 & 11 & 7 & 7 \\
\hline \multirow[t]{3}{*}{ c } & $05 / 25-07 / 31$ & Crowded & 4 & 4 & 6 & 6 & 5 & 5 & 6 & 6 & 4 & 4 & 5 & 5 & 3 & 3 & 6 & 6 \\
\hline & & Mid & 12 & 12 & 10 & 10 & 11 & 11 & 10 & 10 & 12 & 12 & 11 & 11 & 13 & 13 & 10 & 10 \\
\hline & & Uncrowded & 8 & 8 & 8 & 8 & 8 & 8 & 8 & 8 & 8 & 8 & 8 & 8 & 8 & 8 & 8 & 8 \\
\hline \multirow[t]{3}{*}{ D } & $05 / 25-07 / 31$ & Crowded & 8 & 8 & 8 & 8 & 8 & 8 & 8 & 8 & 8 & 8 & 8 & 8 & 8 & 8 & 8 & 8 \\
\hline & & Mid & 8 & 8 & 8 & 8 & 8 & 8 & 8 & 8 & 8 & 8 & 8 & 8 & 8 & 8 & 8 & 8 \\
\hline & & Uncrowded & 8 & 8 & 8 & 8 & 8 & 8 & 8 & 8 & 8 & 8 & 8 & 8 & 8 & 8 & 8 & 8 \\
\hline \multirow[t]{2}{*}{ E } & $05 / 25-07 / 31$ & Crowded & 6 & 6 & 6 & 6 & 6 & 6 & 6 & 6 & 6 & 6 & 6 & 6 & 6 & 6 & 6 & 6 \\
\hline & & Mid & 10 & 10 & 10 & 10 & 10 & 10 & 10 & 10 & 10 & 10 & 10 & 10 & 10 & 10 & 10 & 10 \\
\hline \multirow{2}{*}{$\mathrm{F}$} & & Mid & 12 & 12 & 12 & 12 & 12 & 12 & 12 & 12 & 12 & 12 & 12 & 12 & 12 & 12 & 12 & 12 \\
\hline & & Uncrowded & 8 & 8 & 8 & 8 & 8 & 8 & 8 & 8 & 8 & 8 & 8 & 8 & 8 & 8 & 8 & 8 \\
\hline
\end{tabular}



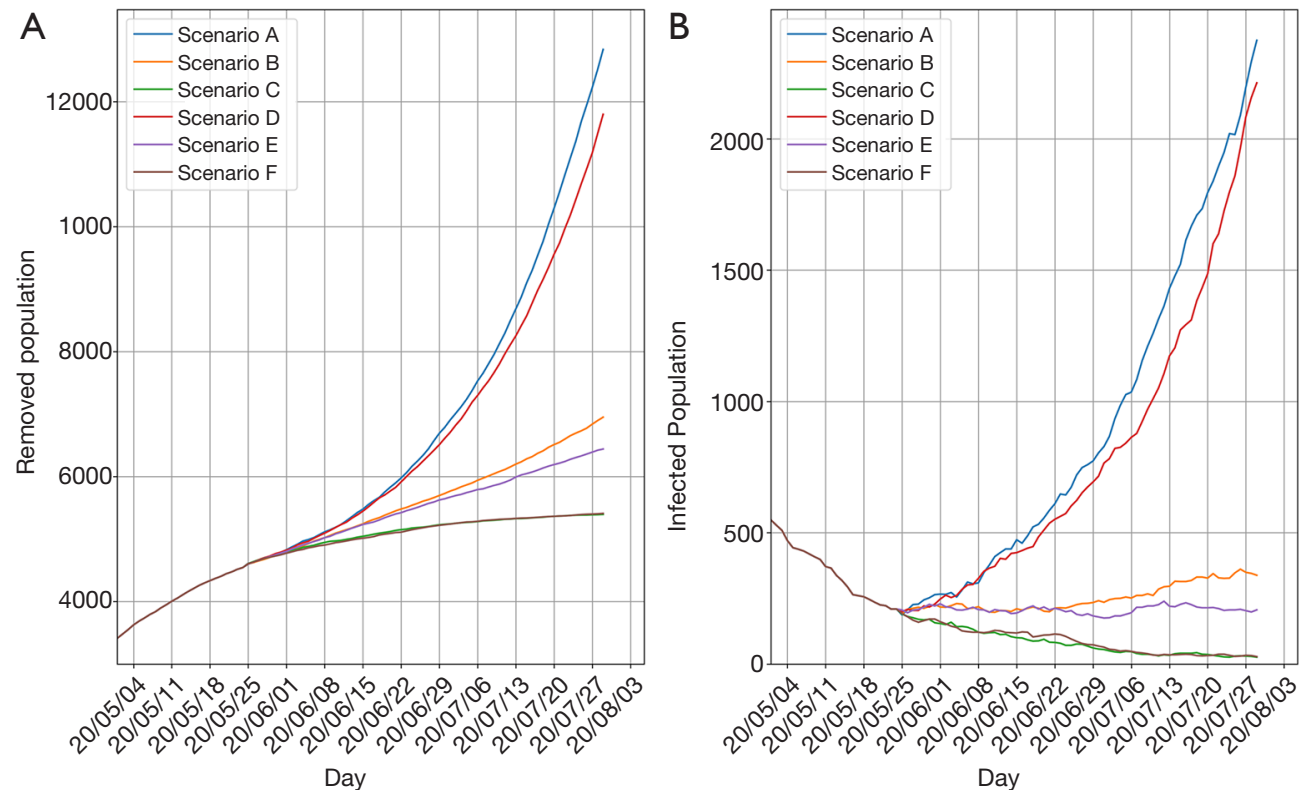

Figure 4 Infection transition in Tokyo predicted in scenarios with different activity levels by localized stochastic transition model. (A) Transition of the number of removed. (B) Transition of the number of infected.
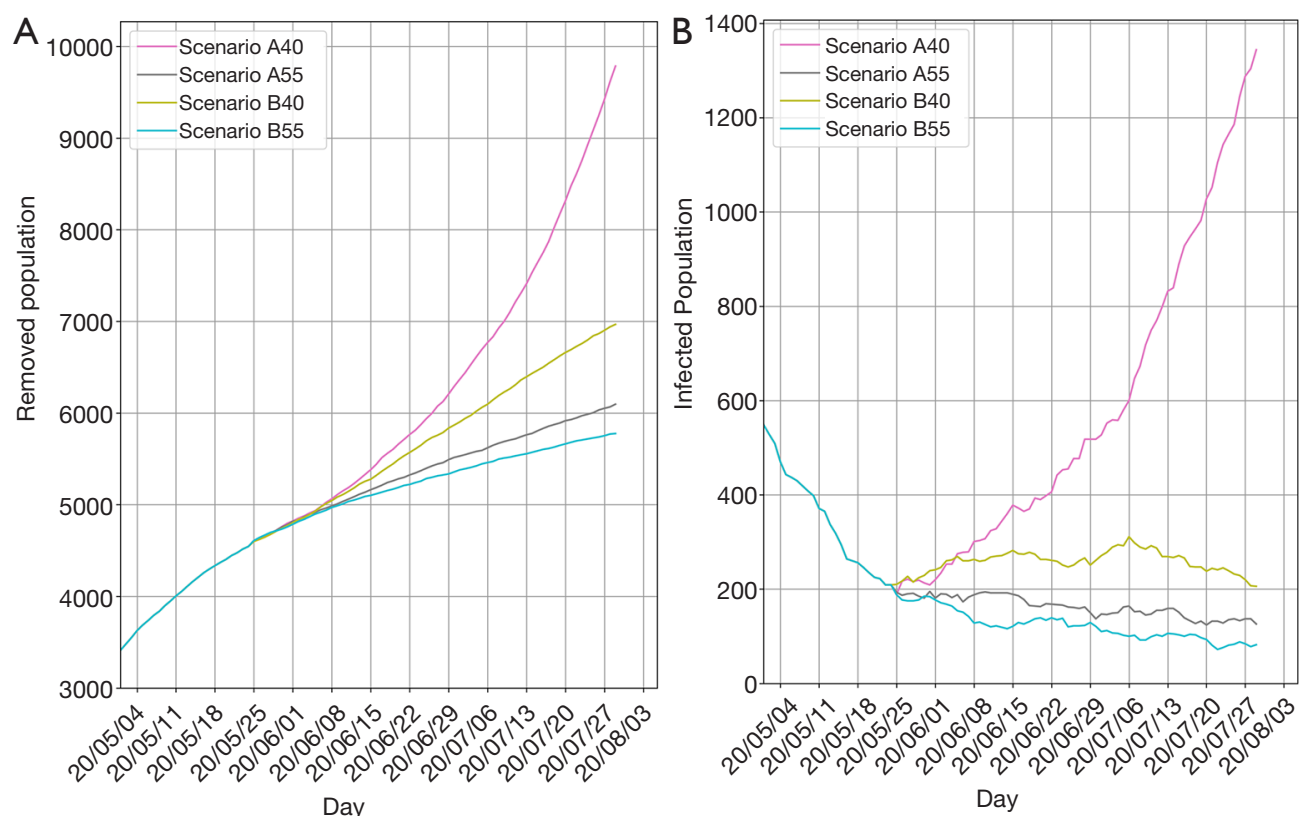

Figure 5 Infection transition in Tokyo predicted in scenarios with different ratio of teleworking by localized stochastic transition model. (A) Transition of the number of removed. (B) Transition of the number of infected. 
situation. Indeed, different people behave in different ways and people tend to change their behavior either due to ageing or responding to the environmental signals, such like the declaration of emergency state by the government.

Measures for the early detection of infected people, such as increasing the number of PCR tests $(31,32)$, as well as measures for cluster intervention $(33,34)$, such as isolating those in close contact with detected infected person, have led to the control of infection in Japan within a short period of 49 days. It is argued that the key mechanism of successfully controlling the spread of infection is that the number of segregated per day should exceed the number of infected per day. Simulations proved that this argument is relevant, by the comparison of time evolution of the infected number under a constant removal probability with that under an increasing one.

According to the simulation results, although the first explosive infection of COVID-19 has been avoided in Tokyo, increasing activities in the city again may lead to a second wave of infections. In fact, Tokyo Metropolitan Government (TMG) decided to move to STEP 2 of the "roadmap for overcoming new coronavirus infectious diseases" (35) from June 1. Correspondingly, self-restraint requests for some industries are lifted in order to restore the state of economy (36). From June 12, TMG decided to move to STEP 3 (37), basically lifting self-restraint requests for all industries. The recent data has already shown that the complete resumption of activities is likely to lead to increasing the number of infected people. As implied by Scenarios B and E, it would be desirable to maintain a partial suppression of activities, though the spread of infection could not subside completely. Based on the simulation of Scenarios C and F, only if a large amount of self-restraint were implemented, the complete convergence could be realized, which, however, might cause a too big economic damage in the meantime.

Teleworking may become a way out of the dilemma between the effective suppression of COVID-19 infection and the evasion of a large scale economic recession. Simulations indicate that when $55 \%$ of working people aged from 20 to 64 change their working style into telework would end the spread of infection without significant economic damage. According to a survey in April (38), $62.7 \%$ of Japanese companies have introduced the telework environment, partly thanks to TMG's support. Also, the survey shows that $49.1 \%$ of the employees were doing telework in April. However, this figure seems to be temporary effect of the state of emergency, we are not sure how many people will do telework after June. The behavior pattern used in Scenarios A55 and B55 also suggest to keep the activity to about $75 \%$ of the normal activity level. In reality, lowering the activity can be achieved not only by forcefully restricting the human activity, but also by reducing chance of staying in an environment with a high probability of infection.

\section{Conclusions}

To summarize, our analysis shows that the major cause for the success of controlling the first outbreak in Tokyo is the early request of self-restraint as well as the early detection of infected people. However, increasing human activities again in the resumption of economy will lead to the second wave of infections. To control the spread of infection while maintaining a certain level of economic activity, it should change the workstyle of $55 \%$ of working people to teleworking and to reduce $25 \%$ time staying in the high infection risk area, the latter of which can be realized by executing infallibly the policy for avoiding "closed spaces, crowded places, and close-contact settings". All in all, this study suggests that to avoid situations with a high probability of infection and to change the regular working into teleworking should become a new lifestyle in face of COVID-19, especially for Tokyo and other cities that with a high population density.

\section{Acknowledgments}

Funding: None.

\section{Footnote}

Conflicts of Interest: All authors have completed the ICMJE uniform disclosure form (available at http://dx.doi. org/10.21037/atm-20-5334). The authors have no conflicts of interest to declare.

Ethical Statement: The authors are accountable for all aspects of the work in ensuring that questions related to the accuracy or integrity of any part of the work are appropriately investigated and resolved.

Open Access Statement: This is an Open Access article distributed in accordance with the Creative Commons Attribution-NonCommercial-NoDerivs 4.0 International License (CC BY-NC-ND 4.0), which permits the non- 
commercial replication and distribution of the article with the strict proviso that no changes or edits are made and the original work is properly cited (including links to both the formal publication through the relevant DOI and the license). See: https://creativecommons.org/licenses/by-nc-nd/4.0/.

\section{References}

1. Lu R, Zhao X, Li J, et al. Genomic characterisation and epidemiology of 2019 novel coronavirus: implications for virus origins and receptor binding. Lancet 2020;395:565-74.

2. Guan WJ, Ni ZY, Hu Y, et al. Clinical Characteristics of Coronavirus Disease 2019 in China. N Engl J Med 2020;382:1708-20.

3. Meng X, Ling $\mathrm{Y}$, Zhang L, et al. Potential for jaktinib hydrochloride to treat cytokine storms in patients with COVID-19. Biosci Trends 2020;14:161-7.

4. Hu Z, Song C, Xu C, et al. Clinical characteristics of 24 asymptomatic infections with COVID-19 screened among close contacts in Nanjing, China. Sci China Life Sci 2020;63:706-11.

5. Nakamura K, Ide S, Saito S, et al. COVID-19 can suddenly become severe: a case series from Tokyo, Japan. Global Health \& Medicine 2020;2:174-7.

6. Guo G, Ye L, Pan K, et al. New Insights of Emerging SARS-CoV-2: Epidemiology, Etiology, Clinical Features, Clinical Treatment, and Prevention. Front Cell Dev Biol 2020;8:410.

7. Ito K, Ohmagari N, Mikami A, et al. Major ongoing clinical trials for COVID-19 treatment and studies currently being conducted or scheduled in Japan. Global Health \& Medicine 2020;2:96-101.

8. World Health Organization. WHO Director-General's opening remarks at the media briefing on COVID-19 -11 March 2020. Available online: https://www.who.int/dg/ speeches/detail/who-director-general-s-opening-remarksat-the-media-briefing-on-covid-19---11-march-2020

9. COVID-19 Dashboard by the Center for Systems Science and Engineering (CSSE) at Johns Hopkins University (JHU). Updated at 7/11/2020. Available online: https:// www.coronavirus.jhu.edu/map.html

10. Ministry of Health, Labor and Welfare, Japan. About Coronavirus Disease 2019 (COVID-19). Available online: https://www.mhlw.go.jp/stf/newpage_12377.html

11. Inoue H. Japanese strategy to COVID-19: How does it work? Global Health \& Medicine 2020;2:131-2.

12. Ministry of Health, Labor and Welfare, Japan. About New
Coronavirus Infections on April 4, 2020. Available online: https://www.mhlw.go.jp/stf/newpage_10696.html

13. Tokyo Metropolitan Government. The number of confirmed cases in Tokyo. 2020. Available online: https://catalog.data.metro.tokyo.lg.jp/dataset/ t000010d0000000068

14. Prime Minister of Japan and His Cabinet. [COVID-19] Press Conference by the Prime Minister Regarding the Declaration of a State of Emergency. April 7, 2020. Available online: https://www.kantei.go.jp/jp/98_abe/ actions/202004/07 corona.html

15. Prime Minister of Japan and His Cabinet. [COVID-19] Press Conference by the Prime Minister regarding the Novel Coronavirus. May 25, 2020. Available online: https://japan.kantei.go.jp/98_abe/ statement/202005/_00003.html

16. Ministry of Health, Labor and Welfare, Japan. About New Coronavirus Infections on 25 May 2020. Available online: https://www.mhlw.go.jp/stf/newpage_11504.html

17. Tokyo Metropolitan Government. The new cases with COVID-19 reported in Tokyo. Available online: https://stopcovid19.metro.tokyo.lg.jp/cards/number-ofconfirmed-cases/

18. Karako K, Song P, Chen Y, et al. Analysis of COVID-19 infection spread in Japan based on stochastic transition model. BioSci Trends 2020;14:134-8.

19. Kuniya T. Prediction of the Epidemic Peak of Coronavirus Disease in Japan, J Clin Med 2020;9:789.

20. Kobayashi G, Sugasawa S, Tamae H, et al. Predicting intervention effect for COVID-19 in Japan: state space modeling approach. BioSci Trends 2020;14:174-81.

21. Tokyo Metropolitan Government. Overview of daytime population in Tokyo. 2020. Available online: https://www.metro.tokyo.lg.jp/tosei/hodohappyo/ press/2018/03/20/12.html

22. Tokyo Metropolitan Government. Living and Statistics 2019 (Population and Households). 2020. Available online: https://www.toukei.metro.tokyo.lg.jp/kurasi/2019/ku1904.htm

23. Chiba Prefectral Government. Chiba Prefecture Population by Age/City. 2020. Available online: https:// www.pref.chiba.lg.jp/toukei/toukeidata/nenreibetsu/h30/ h30-index.html

24. Kanagawa Prefectural Government. Kanagawa Prefecture Demographic Survey Results by Age. 2020. Available online: https://www.pref.kanagawa.jp/docs/x6z/tc30/jinko/ nenreibetu.html

25. Saitama Prefectural Government. Time series data of age 
structure. 2020. Available online: https://www.pref.saitama. lg.jp/a0206/a009/age.html

26. Gunma Prefectural Government. Population of Gunma Prefecture by Age. 2020. Available online: https://toukei. pref.gunma.jp/nbj

27. Tochigi Prefectural Government. Results of census by age. 2020. Available online: http://www.pref.tochigi.lg.jp/c04/ pref/toukei/toukei/popu2.html

28. Ibaraki Prefectural Government. Population of Ibaraki Prefecture by Age. 2020. Available online: https://www. pref.ibaraki.jp/kikaku/tokei/fukyu/tokei/betsu/jinko/ nenrei/index.html

29. GIS/J.A.G. Dashboard \& Map of COVID-19 Japan Case. 2020. Available online: https://gis.jag-japan.com/covid19jp

30. Tokyo Metropolitan Government. Changes in the number of railway users. 2020 Available online: https://smooth-biz. metro.tokyo.lg.jp/pdf/202004date3.pdf

31. Ministry of Health, Labor and Welfare, Japan. Implementation status of PCR tests for COVID-19 in Japan. 2020. Available online: https://www.mhlw.go.jp/ content/10906000/000630894.pdf

32. Kutsuna S. Coronavirus disease 2019 (COVID-19): research progress and clinical practice. Global Health \& Medicine 2020;2:78-88.

Cite this article as: Karako $\mathrm{K}$, Song $\mathrm{P}$, Chen Y, Tang W. Shifting workstyle to teleworking as a new normal in face of COVID-19: analysis with the model introducing intercity movement and behavioral pattern. Ann Transl Med 2020;8(17):1056. doi: 10.21037/atm-20-5334
33. Ministry of Health, Labor and Welfare, Japan. Measures for patient clusters in new coronavirus infections. 2020. Available online: https://www.mhlw.go.jp/ content/000619966.pdf

34. Kuwahara K, Hori A, Ohmagari N, et al. Early cases of COVID-19 in Tokyo and occupational health. Global Health \& Medicine 2020;2:118-22.

35. Tokyo Metropolitan Government. Roadmap for overcoming new coronavirus infectious diseases. 2020. Available online: https://www.bousai.metro.tokyo. lg.jp/1007942/1007957.html

36. Tokyo Metropolitan Government. Measures to prevent the spread of new coronavirus infection in step 2. 2020. Available online: https://www.bousai.metro.tokyo. lg.jp/1007942/1008165.html

37. Tokyo Metropolitan Government. Measures to prevent the spread of new coronavirus infection in step 3. 2020. Available online: https://www.bousai.metro.tokyo. lg.jp/1007942/1008452.html

38. Tokyo Metropolitan Government. Results of the urgent survey about telework introduction rate. 2020. Available online: https://www.metro.tokyo.lg.jp/tosei/hodohappyo/ press/2020/05/12/10.html 
Supplementary

Table S1 Initial population of susceptible, infected, removed in each city

\begin{tabular}{|c|c|c|c|c|c|}
\hline \multirow{2}{*}{ City } & \multirow{2}{*}{ Subgroup } & \multicolumn{4}{|c|}{ Initial population in each city } \\
\hline & & Susceptible & Infected & Removed & Total \\
\hline \multicolumn{6}{|l|}{ Tokyo } \\
\hline \multicolumn{6}{|l|}{ Age } \\
\hline \multirow[t]{2}{*}{ 0-19 } & Normal & $1,889,995$ & 4 & 1 & $1,890,000$ \\
\hline & Active & 210,000 & 0 & 0 & 210,000 \\
\hline \multirow[t]{4}{*}{$20-64$} & Normal & $2,459,909$ & 65 & 26 & $2,460,000$ \\
\hline & Active & 820,000 & 0 & 0 & 820,000 \\
\hline & Complete telework & $2,050,000$ & 0 & 0 & $2,050,000$ \\
\hline & Partial telework & $2,870,000$ & 0 & 0 & $2,870,000$ \\
\hline $65 \sim$ & Normal & $2,699,966$ & 24 & 10 & $2,700,000$ \\
\hline & Active & 300,000 & 0 & 0 & 300,000 \\
\hline Total & & $13,299,870$ & 93 & 37 & $13,300,000$ \\
\hline Chiba & & & & & \\
\hline Age & & & & & \\
\hline $0-19$ & Normal & 989,998 & 1 & 1 & 990,000 \\
\hline & Active & 110,000 & 0 & 0 & 110,000 \\
\hline $20-64$ & Normal & $1,079,972$ & 17 & 11 & $1,080,000$ \\
\hline & Active & 360,000 & 0 & 0 & 360,000 \\
\hline & Complete telework & 900,000 & 0 & 0 & 900,000 \\
\hline & Partial telework & $1,260,000$ & 0 & 0 & $1,260,000$ \\
\hline $65 \sim$ & Normal & $1,529,990$ & 6 & 4 & $1,530,000$ \\
\hline & Active & 170,000 & 0 & 0 & 170,000 \\
\hline Total & & $6,399,960$ & 24 & 16 & $6,400,000$ \\
\hline Kanagawa & & & & & \\
\hline Age & & & & & \\
\hline $0-19$ & Normal & $1,349,998$ & 1 & 1 & $1,350,000$ \\
\hline & Active & 150,000 & 0 & 0 & 150,000 \\
\hline $20-64$ & Normal & $1,589,955$ & 27 & 18 & $1,590,000$ \\
\hline & Active & 530,000 & 0 & 0 & 530,000 \\
\hline & Complete telework & $1,325,000$ & 0 & 0 & $1,325,000$ \\
\hline & Partial telework & $1,855,000$ & 0 & 0 & $1,855,000$ \\
\hline 65 & Normal & $2,069,987$ & 6 & 7 & $2,070,000$ \\
\hline & Active & 230,000 & 0 & 0 & 230,000 \\
\hline Total & & $9,099,940$ & 34 & 26 & $9,100,000$ \\
\hline Saitama & & & & & \\
\hline Age & & & & & \\
\hline $0-19$ & Normal & $1,080,000$ & 0 & 0 & $1,080,000$ \\
\hline & Active & 120,000 & 0 & 0 & 120,000 \\
\hline $20-64$ & Normal & $1,259,993$ & 4 & 3 & $1,260,000$ \\
\hline & Active & 420,000 & 0 & 0 & 420,000 \\
\hline & Complete telework & $1,050,000$ & 0 & 0 & $1,050,000$ \\
\hline & Partial telework & $1,470,000$ & 0 & 0 & $1,470,000$ \\
\hline $65 \sim$ & Normal & $1,709,997$ & 2 & 1 & $1,710,000$ \\
\hline & Active & 190,000 & 0 & 0 & 190,000 \\
\hline Total & & $7,299,990$ & 6 & 4 & $7,300,000$ \\
\hline Gunma & & & & & \\
\hline Age & & & & & \\
\hline $0-19$ & Normal & 270,000 & 0 & 0 & 270,000 \\
\hline & Active & 30,000 & 0 & 0 & 30,000 \\
\hline $20-64$ & Normal & 300,000 & 0 & 0 & 300,000 \\
\hline & Active & 100,000 & 0 & 0 & 100,000 \\
\hline & Complete telework & 250,000 & 0 & 0 & 250,000 \\
\hline & Partial telework & 350,000 & 0 & 0 & 350,000 \\
\hline $65 \sim$ & Normal & 540,000 & 0 & 0 & 540,000 \\
\hline & Active & 60,000 & 0 & 0 & 60,000 \\
\hline Total & & $1,900,000$ & 0 & 0 & $1,900,000$ \\
\hline Tochigi & & & & & \\
\hline Age & & & & & \\
\hline 0-19 & Normal & 270,000 & 0 & 0 & 270,000 \\
\hline & Active & 30,000 & 0 & 0 & 30,000 \\
\hline $20-64$ & Normal & 299,997 & 2 & 1 & 300,000 \\
\hline & Active & 100,000 & 0 & 0 & 100,000 \\
\hline & Complete telework & 250,000 & 0 & 0 & 250,000 \\
\hline & Partial telework & 350,000 & 0 & 0 & 350,000 \\
\hline 65 & Normal & 540,000 & 0 & 0 & 540,000 \\
\hline & Active & 60,000 & 0 & 0 & 60,000 \\
\hline Total & & $1,899,997$ & 2 & 1 & $1,900,000$ \\
\hline Ibaraki & & & & & \\
\hline Age & & & & & \\
\hline $0-19$ & Normal & 450,000 & 0 & 0 & 450,000 \\
\hline & Active & 50,000 & 0 & 0 & 50,000 \\
\hline $20-64$ & Normal & 480,000 & 0 & 0 & 480,000 \\
\hline & Active & 160,000 & 0 & 0 & 160,000 \\
\hline & Complete telework & 400,000 & 0 & 0 & 400,000 \\
\hline & Partial telework & 560,000 & 0 & 0 & 560,000 \\
\hline $65 \sim$ & Normal & 720,000 & 0 & 0 & 720,000 \\
\hline & Active & 80,000 & 0 & 0 & 80,000 \\
\hline Total & & $2,900,000$ & 0 & 0 & $2,900,000$ \\
\hline
\end{tabular}


Table S2 Behavioral pattern of each group that represents the time spent per day in each zone

\begin{tabular}{|c|c|c|c|c|c|c|c|c|c|c|c|c|c|c|c|c|c|}
\hline \multirow{4}{*}{ Term } & \multirow{4}{*}{ Zone } & \multicolumn{16}{|c|}{ Time staying at each place per day (hour) } \\
\hline & & \multicolumn{4}{|c|}{ Age: $20-19$} & \multicolumn{8}{|c|}{ Age: $20-64$} & \multicolumn{4}{|c|}{ Age: 65 } \\
\hline & & \multicolumn{2}{|c|}{ Normal } & \multicolumn{2}{|c|}{ Active } & \multicolumn{2}{|c|}{ Normal } & \multicolumn{2}{|c|}{ Active } & \multicolumn{2}{|c|}{ Complete telework } & \multicolumn{2}{|c|}{ Partial telework } & \multicolumn{2}{|c|}{ Normal } & \multicolumn{2}{|c|}{ Active } \\
\hline & & Weekdays & Holidays & Weekdays & Holidays & Weekdays & Holidays & Weekdays & Holidays & Weekdays & Holidays & Weekdays & Holidays & Weekdays & Holidays & Weekdays & Holidays \\
\hline \multirow[t]{3}{*}{ 03/01-03/19 } & Crowded & 4 & 4 & 12 & 12 & 10 & 10 & 12 & 12 & 4 & 8 & 10 & 10 & 6 & 6 & 12 & 12 \\
\hline & Mid & 12 & 12 & 6 & 6 & 6 & 6 & 6 & 6 & 12 & 8 & 6 & 6 & 10 & 10 & 6 & 6 \\
\hline & Uncrowded & 8 & 8 & 6 & 6 & 8 & 8 & 6 & 6 & 8 & 8 & 8 & 8 & 8 & 8 & 6 & 6 \\
\hline \multirow[t]{3}{*}{ 03/20-04/06 } & Crowded & 5 & 5 & 12 & 12 & 10 & 12 & 12 & 12 & 4 & 10 & 10 & 12 & 7 & 7 & 12 & 12 \\
\hline & Mid & 11 & 11 & 6 & 6 & 6 & 4 & 6 & 6 & 12 & 6 & 6 & 4 & 9 & 9 & 6 & 6 \\
\hline & Uncrowded & 8 & 8 & 6 & 6 & 8 & 8 & 6 & 6 & 8 & 8 & 8 & 8 & 8 & 8 & 6 & 6 \\
\hline \multirow[t]{3}{*}{$04 / 07-04 / 13$} & Crowded & 3 & 3 & 10 & 10 & 8 & 4 & 10 & 10 & 4 & 4 & 4 & 4 & 5 & 4 & 10 & 10 \\
\hline & Mid & 13 & 13 & 6 & 6 & 8 & 12 & 6 & 6 & 12 & 12 & 12 & 12 & 11 & 12 & 6 & 6 \\
\hline & Uncrowded & 8 & 8 & 8 & 8 & 8 & 8 & 8 & 8 & 8 & 8 & 8 & 8 & 8 & 8 & 8 & 8 \\
\hline \multirow[t]{3}{*}{$04 / 14-04 / 20$} & Crowded & 2 & 2 & 8 & 8 & 5 & 2 & 8 & 8 & 3 & 2 & 3 & 2 & 3 & 3 & 8 & 8 \\
\hline & Mid & 14 & 14 & 8 & 8 & 11 & 14 & 8 & 8 & 13 & 14 & 13 & 14 & 13 & 13 & 8 & 8 \\
\hline & Uncrowded & 8 & 8 & 8 & 8 & 8 & 8 & 8 & 8 & 8 & 8 & 8 & 8 & 8 & 8 & 8 & 8 \\
\hline \multirow[t]{3}{*}{$04 / 21-04 / 27$} & Crowded & 1 & 1 & 6 & 6 & 4 & 1 & 6 & 6 & 2 & 1 & 2 & 1 & 2 & 1 & 6 & 6 \\
\hline & Mid & 15 & 15 & 10 & 10 & 12 & 15 & 10 & 10 & 14 & 15 & 14 & 15 & 14 & 15 & 10 & 10 \\
\hline & Uncrowded & 8 & 8 & 8 & 8 & 8 & 8 & 8 & 8 & 8 & 8 & 8 & 8 & 8 & 8 & 8 & 8 \\
\hline \multirow[t]{3}{*}{$04 / 28-05 / 04$} & Crowded & 1 & 1 & 6 & 6 & 4 & 1 & 6 & 6 & 2 & 1 & 2 & 1 & 2 & 1 & 6 & 6 \\
\hline & Mid & 15 & 15 & 10 & 10 & 12 & 15 & 10 & 10 & 14 & 15 & 14 & 15 & 14 & 15 & 10 & 10 \\
\hline & Uncrowded & 8 & 8 & 8 & 8 & 8 & 8 & 8 & 8 & 8 & 8 & 8 & 8 & 8 & 8 & 8 & 8 \\
\hline \multirow[t]{3}{*}{ 05/05-05/24 } & Crowded & 2 & 2 & 8 & 8 & 5 & 2 & 8 & 8 & 3 & 2 & 3 & 2 & 3 & 3 & 8 & 8 \\
\hline & Mid & 14 & 14 & 8 & 8 & 11 & 14 & 8 & 8 & 13 & 14 & 13 & 14 & 13 & 13 & 8 & 8 \\
\hline & Uncrowded & 8 & 8 & 8 & 8 & 8 & 8 & 8 & 8 & 8 & 8 & 8 & 8 & 8 & 8 & 8 & 8 \\
\hline
\end{tabular}




\begin{tabular}{|c|c|c|c|c|c|c|c|c|}
\hline \multirow{3}{*}{ Term } & \multirow{3}{*}{ To } & \multicolumn{7}{|c|}{ Percentage of people moving between cities per day } \\
\hline & & \multicolumn{7}{|c|}{ From } \\
\hline & & Tokyo & Chiba & Kanagawa & Saitama & Gunma & Tochigi & Ibaraki \\
\hline \multirow[t]{7}{*}{ 03/01-03/19 } & Tokyo & - & $9.0 \%$ & $9.0 \%$ & $9.0 \%$ & $0.9 \%$ & $0.9 \%$ & $0.9 \%$ \\
\hline & Chiba & $1.6 \%$ & - & $3.6 \%$ & $1.8 \%$ & $0.9 \%$ & $0.9 \%$ & $3.6 \%$ \\
\hline & Kanagawa & $1.6 \%$ & $3.6 \%$ & - & $1.8 \%$ & $0.9 \%$ & $0.9 \%$ & $0.9 \%$ \\
\hline & Saitama & $1.6 \%$ & $3.6 \%$ & $3.6 \%$ & - & $3.6 \%$ & $3.6 \%$ & $3.6 \%$ \\
\hline & Gunma & $1.6 \%$ & $0.9 \%$ & $0.9 \%$ & $1.8 \%$ & - & $3.6 \%$ & $3.6 \%$ \\
\hline & Tochigi & $1.6 \%$ & $0.9 \%$ & $0.9 \%$ & $1.8 \%$ & $3.6 \%$ & - & $3.6 \%$ \\
\hline & Ibaraki & $1.6 \%$ & $3.6 \%$ & $0.9 \%$ & $1.8 \%$ & $3.6 \%$ & $3.6 \%$ & - \\
\hline \multirow[t]{7}{*}{ 03/20-04/06 } & Tokyo & - & $10.0 \%$ & $10.0 \%$ & $10.0 \%$ & $1.0 \%$ & $1.0 \%$ & $1.0 \%$ \\
\hline & Chiba & $1.8 \%$ & - & $4.0 \%$ & $2.0 \%$ & $1.0 \%$ & $1.0 \%$ & $4.0 \%$ \\
\hline & Kanagawa & $1.8 \%$ & $4.0 \%$ & - & $2.0 \%$ & $1.0 \%$ & $1.0 \%$ & $1.0 \%$ \\
\hline & Saitama & $1.8 \%$ & $4.0 \%$ & $4.0 \%$ & - & $4.0 \%$ & $4.0 \%$ & $4.0 \%$ \\
\hline & Gunma & $1.8 \%$ & $1.0 \%$ & $1.0 \%$ & $2.0 \%$ & - & $4.0 \%$ & $4.0 \%$ \\
\hline & Tochigi & $1.8 \%$ & $1.0 \%$ & $1.0 \%$ & $2.0 \%$ & $4.0 \%$ & - & $4.0 \%$ \\
\hline & Ibaraki & $1.8 \%$ & $4.0 \%$ & $1.0 \%$ & $2.0 \%$ & $4.0 \%$ & $4.0 \%$ & - \\
\hline \multirow[t]{7}{*}{$04 / 07-04 / 13$} & Tokyo & - & $9.0 \%$ & $9.0 \%$ & $9.0 \%$ & $0.9 \%$ & $0.9 \%$ & $0.9 \%$ \\
\hline & Chiba & $1.3 \%$ & - & $3.6 \%$ & $1.8 \%$ & $0.9 \%$ & $0.9 \%$ & $3.6 \%$ \\
\hline & Kanagawa & $1.3 \%$ & $3.6 \%$ & - & $1.8 \%$ & $0.9 \%$ & $0.9 \%$ & $0.9 \%$ \\
\hline & Saitama & $1.3 \%$ & $3.6 \%$ & $3.6 \%$ & - & $3.6 \%$ & $3.6 \%$ & $3.6 \%$ \\
\hline & Gunma & $1.3 \%$ & $0.9 \%$ & $0.9 \%$ & $1.8 \%$ & - & $3.6 \%$ & $3.6 \%$ \\
\hline & Tochigi & $1.3 \%$ & $0.9 \%$ & $0.9 \%$ & $1.8 \%$ & $3.6 \%$ & - & $3.6 \%$ \\
\hline & Ibaraki & $1.3 \%$ & $3.6 \%$ & $0.9 \%$ & $1.8 \%$ & $3.6 \%$ & $3.6 \%$ & - \\
\hline \multirow[t]{7}{*}{$04 / 14-04 / 20$} & Tokyo & - & $6.0 \%$ & $6.0 \%$ & $6.0 \%$ & $0.6 \%$ & $0.6 \%$ & $0.6 \%$ \\
\hline & Chiba & $1.0 \%$ & - & $2.4 \%$ & $1.2 \%$ & $0.6 \%$ & $0.6 \%$ & $2.4 \%$ \\
\hline & Kanagawa & $1.0 \%$ & $2.4 \%$ & - & $1.2 \%$ & $0.6 \%$ & $0.6 \%$ & $0.6 \%$ \\
\hline & Saitama & $1.0 \%$ & $2.4 \%$ & $2.4 \%$ & - & $2.4 \%$ & $2.4 \%$ & $2.4 \%$ \\
\hline & Gunma & $1.0 \%$ & $0.6 \%$ & $0.6 \%$ & $1.2 \%$ & - & $2.4 \%$ & $2.4 \%$ \\
\hline & Tochigi & $1.0 \%$ & $0.6 \%$ & $0.6 \%$ & $1.2 \%$ & $2.4 \%$ & - & $2.4 \%$ \\
\hline & Ibaraki & $1.0 \%$ & $2.4 \%$ & $0.6 \%$ & $1.2 \%$ & $2.4 \%$ & $2.4 \%$ & - \\
\hline \multirow[t]{7}{*}{$04 / 21-04 / 27$} & Tokyo & - & $6.0 \%$ & $6.0 \%$ & $6.0 \%$ & $0.6 \%$ & $0.6 \%$ & $0.6 \%$ \\
\hline & Chiba & $0.8 \%$ & - & $2.4 \%$ & $1.2 \%$ & $0.6 \%$ & $0.6 \%$ & $2.4 \%$ \\
\hline & Kanagawa & $0.8 \%$ & $2.4 \%$ & - & $1.2 \%$ & $0.6 \%$ & $0.6 \%$ & $0.6 \%$ \\
\hline & Saitama & $0.8 \%$ & $2.4 \%$ & $2.4 \%$ & - & $2.4 \%$ & $2.4 \%$ & $2.4 \%$ \\
\hline & Gunma & $0.8 \%$ & $0.6 \%$ & $0.6 \%$ & $1.2 \%$ & - & $2.4 \%$ & $2.4 \%$ \\
\hline & Tochigi & $0.8 \%$ & $0.6 \%$ & $0.6 \%$ & $1.2 \%$ & $2.4 \%$ & - & $2.4 \%$ \\
\hline & Ibaraki & $0.8 \%$ & $2.4 \%$ & $0.6 \%$ & $1.2 \%$ & $2.4 \%$ & $2.4 \%$ & - \\
\hline \multirow[t]{7}{*}{ 04/28-05/04 } & Tokyo & - & $6.0 \%$ & $6.0 \%$ & $6.0 \%$ & $0.6 \%$ & $0.6 \%$ & $0.6 \%$ \\
\hline & Chiba & $0.8 \%$ & - & $2.4 \%$ & $1.2 \%$ & $0.6 \%$ & $0.6 \%$ & $2.4 \%$ \\
\hline & Kanagawa & $0.8 \%$ & $2.4 \%$ & - & $1.2 \%$ & $0.6 \%$ & $0.6 \%$ & $0.6 \%$ \\
\hline & Saitama & $0.8 \%$ & $2.4 \%$ & $2.4 \%$ & - & $2.4 \%$ & $2.4 \%$ & $2.4 \%$ \\
\hline & Gunma & $0.8 \%$ & $0.6 \%$ & $0.6 \%$ & $1.2 \%$ & - & $2.4 \%$ & $2.4 \%$ \\
\hline & Tochigi & $0.8 \%$ & $0.6 \%$ & $0.6 \%$ & $1.2 \%$ & $2.4 \%$ & - & $2.4 \%$ \\
\hline & Ibaraki & $0.8 \%$ & $2.4 \%$ & $0.6 \%$ & $1.2 \%$ & $2.4 \%$ & $2.4 \%$ & - \\
\hline \multirow[t]{7}{*}{ 05/05-05/24 } & Tokyo & - & $7.0 \%$ & $7.0 \%$ & $7.0 \%$ & $0.7 \%$ & $0.7 \%$ & $0.7 \%$ \\
\hline & Chiba & $0.8 \%$ & - & $2.8 \%$ & $1.4 \%$ & $0.7 \%$ & $0.7 \%$ & $2.8 \%$ \\
\hline & Kanagawa & $0.8 \%$ & $2.8 \%$ & - & $1.4 \%$ & $0.7 \%$ & $0.7 \%$ & $0.7 \%$ \\
\hline & Saitama & $0.8 \%$ & $2.8 \%$ & $2.8 \%$ & - & $2.8 \%$ & $2.8 \%$ & $2.8 \%$ \\
\hline & Gunma & $0.8 \%$ & $0.7 \%$ & $0.7 \%$ & $1.4 \%$ & - & $2.8 \%$ & $2.8 \%$ \\
\hline & Tochigi & $0.8 \%$ & $0.7 \%$ & $0.7 \%$ & $1.4 \%$ & $2.8 \%$ & - & $2.8 \%$ \\
\hline & Ibaraki & $0.8 \%$ & $2.8 \%$ & $0.7 \%$ & $1.4 \%$ & $2.8 \%$ & $2.8 \%$ & - \\
\hline \multirow[t]{7}{*}{$05 / 25-07 / 31$} & Tokyo & - & $9.0 \%$ & $9.0 \%$ & $9.0 \%$ & $0.9 \%$ & $0.9 \%$ & $0.9 \%$ \\
\hline & Chiba & $1.6 \%$ & - & $3.6 \%$ & $1.8 \%$ & $0.9 \%$ & $0.9 \%$ & $3.6 \%$ \\
\hline & Kanagawa & $1.6 \%$ & $3.6 \%$ & - & $1.8 \%$ & $0.9 \%$ & $0.9 \%$ & $0.9 \%$ \\
\hline & Saitama & $1.6 \%$ & $3.6 \%$ & $3.6 \%$ & - & $3.6 \%$ & $3.6 \%$ & $3.6 \%$ \\
\hline & Gunma & $1.6 \%$ & $0.9 \%$ & $0.9 \%$ & $1.8 \%$ & - & $3.6 \%$ & $3.6 \%$ \\
\hline & Tochigi & $1.6 \%$ & $0.9 \%$ & $0.9 \%$ & $1.8 \%$ & $3.6 \%$ & - & $3.6 \%$ \\
\hline & Ibaraki & $1.6 \%$ & $3.6 \%$ & $0.9 \%$ & $1.8 \%$ & $3.6 \%$ & $3.6 \%$ & - \\
\hline
\end{tabular}


Table S4 Baseline removal probability $\beta_{\text {term }}$ used for each term and pattern

\begin{tabular}{lcc}
\hline \multirow{2}{*}{ Term } & \multicolumn{2}{c}{$\beta_{\text {term }}$} \\
\cline { 2 - 3 } & Increasing $P_{\text {Removed }}$ & Constant $P_{\text {Removed }}$ \\
\hline $03 / 01-03 / 19$ & $10.0 \%$ & $10.0 \%$ \\
$03 / 20-04 / 06$ & $10.0 \%$ & $10.0 \%$ \\
$04 / 07-04 / 13$ & $10.0 \%$ & $10.0 \%$ \\
$04 / 14-04 / 20$ & $12.0 \%$ & $10.0 \%$ \\
$04 / 21-04 / 27$ & $12.0 \%$ & $10.0 \%$ \\
$04 / 28-05 / 04$ & $14.0 \%$ & $10.0 \%$ \\
$05 / 05-05 / 24$ & $14.0 \%$ & $10.0 \%$ \\
\hline
\end{tabular}

